\title{
Research on the Coordinated Development Strategy of Green Sustainable Design and Rural Ecological Landscape
}

\author{
Qianqian Zhang \\ Xiamen University Tan Kah Kee College \\ Xiamen, Fujian 363105, China
}

\begin{abstract}
In the process of rapid urbanization in our country, the state has been seeking the model for the development of characteristic industries in cities and towns and establishing the leading characteristic industry in the urbanization. The purpose is to enhance the attractiveness and core competitiveness of the rural ecological industry and promote the active and rational flow of population with the construction of ecological villages, so as to ensure the smooth urbanization in China. However, the corresponding green sustainable design and development of rural construction as well as the corresponding green design model have not been formed yet, and corresponding researches in China are still in exploration. By analyzing the status quo of eco-villages in Fujian Province, the author took the industrial ecological economics as a guide and drew lessons from cross-disciplinary basic disciplines such as fractal theory of town planning, habitat theory of landscape ecology and information processing theory, and then came up with guiding principles for rural ecological development under the theoretical framework of "green sustainable design". The evaluation system for the development of rural ecological construction is also formulated in this article to guide the medium and long-term planning principles and specific implementation strategies for eco-village construction, with the purpose to achieve sustainable and coordinated development of the society, economy and ecology in towns and villages to create a "production, living and ecology" trinitarian mode for the rural ecological construction.
\end{abstract}

Keywords—green sustainability; ecological landscape; strategy research

\section{INTRODUCTION}

In the government's call to "build beautiful villages”, rural transformation has become a local construction boom in these days. However, the rapid development of society generates "hollow villages" in the countryside, resulting in the low vitality of these villages. How to improve the vitality of these villages to achieve sustainable development has become the focus of rural landscape planning and reconstruction. The reconstruction design is not only to improve the rural natural environment, but also to remedy the phenomenon "hollow villages". It is feasible to promote the interaction of nature, society and economy on the basis of respect for the local villagers' way of life, so as to attract the return of young migrant workers and visitors, injecting new vitality into the aging villages. In the design, it is needed to reform the public space of the villages to increase the communication and

Fund Project: 2017 Education and Research Project of Young and Middle-aged Teachers of Fujian Province. No.: JAS170790 activity of villagers; and meanwhile, attention should be given to perfect the faith culture and the natural resources to develop tourism, expand the industrial structure and inject vitality.

\section{BACKGROUND STUDY}

The megatrends in China like urbanization of villages, the urbanization of villagers, the industrialization of villages and the integration of urban and rural areas are promoting the rise of new villages. In this context, traditional villages are gradually disappearing and the village cultures are slowly declining and decaying. According to the related data of villages and towns, Fujian Province has 9 prefecture-level cities, 14 county-level cities, 46 counties, 25 municipal districts, 628 towns, 367 townships, 18 nationality townships and 113 streets. At the end of 2013, there were 37.74 million permanent residents in the province, including 22.93 million in cities and towns and 14.81 million in rural areas. According to the characteristics like the topography and landform, history and humanity and ecological industry type, the villages and towns of Fujian Province are divided into four regions (the north of Fujian, the east of Fujian, the west of Fujian and the south of Fujian) to study the forms of rural characteristic industrial structure.

For example, there has been large-scale breeding industry (pig farm) in Zhangzhou villages in southern Fujian, and the unscientific and disorderly discharge system has brought serious threats to the primitive natural environment of these villages. Increasingly serious pollution (including soil acidbase imbalance, crop production, air quality decline, drinking water pollution, etc.) has affected the villagers' life to a certain extent. In the face of this dilemma, villagers are eager to deal with the pollution problem. Therefore, in addition to improving pollution situation, importance must be attached to promoting the construction and development of rural landscape, improving the overall economic development level of the villages, making full efforts to create ecological recycling and regenerating demonstration villages, so as to finally realize the integration of urban and rural areas.

III. RESEARCH ON THE RELATIONSHIP BETWEEN GREEN SUSTAINABLE DESIGN AND RURAL ECOLOGICAL CONSTRUCTION

The ecological process can be divided into the vertical process and horizontal process [1]. Based on the stage 
characteristics of the accumulation and development of cultural industry, it is necessary to adopt the coupling and linkage form of regional culture, ecological environment design and creative cultural industry design, and highlight the development and design mode of eco-rural construction which is dominated by sustainability.

It is needed to combine the specific regional and rural characteristics and take into account the actual basic condition of various aspects such as the humanity, ecology and culture to implement integration and transformation, so as to build a development model which takes the cooperative mechanism of ecological culture as the core.

Country is a kind of space for human's survival and development and has evolved rural landscapes through adaptation and transformation of nature, as a result of human survival and production needs. As a new type of rural economic construction model, ecology-cyclic landscape is designed to optimize the construction of rural ecology-cyclic landscape in both the green sustainability and ecological systems. A holistic approach can be used to effectively manage rural environmental issues and promote the realization of integrated value of new rural agriculture. It should be based on the goal of coordination and win-win of the constituent factors. From the perspective of rural environment, rural economy and rural life, it is needed to use scientific and technological means to reconstruct the ecological landscape and shape the ecological value of a virtuous circle. It is necessary to combine good local natural environment and resource advantages to return to the nature of rural areas and recreate the balanced and healthy development of rural nature and social economy. Only by constructing green sustainable villages can we form a symbiosis between people and nature and establish a link between urban and rural areas.

\section{PRACTICAL RESEARCH ON THE DEVELOPMENT AND PROTECTION OF RURAL ECOLOGICAL CONSTRUCTION}

In the aspect of ecological rural construction, it is necessary to establish a holistic concept to protect the rural ecological environment as a whole. Eco-village is based on the rural ecological environment. Once it is separated from the rural eco-environment, the eco-village loses its foundation. While protecting the rural eco-environment, it is necessary to develop the special industries to form a harmonious and sustainable green design system. In terms of landscape function planning, different land units have different ecosystem functions which can be mainly divided into three types, namely biological production, environmental services and cultural support [2].

Based on the base investigation and the status quo analysis of the Gaoceng Village in Ganzhou City, it is proposed that the rural landscape must be placed in three aspects: the natural habitat, economic production and living. The purpose is to solve the existing pollution in the villages, update its ecological development model and guide the healthy and balanced development of the rural landscape system during the economic and social transformation.

Landscape is a whole of a series of ecological systems and also a mosaic assembly of various types of land units [3]. As a space of human beings to achieve basic survival and development, rural areas have evolved rural landscapes through adaptation and transformation of nature due to human survival and production needs. The ecology-cyclic landscape, as a new model of rural agriculture, creates a basic pattern for the road to modernization with Chinese characteristics in three aspects: landscape level, ecosystem and community composition. Based on the analysis of recycling agriculture and using the ecological structure and evolution process of villages' natural formation, the concept of ecological pattern featured by ecological agricultural landscape was proposed from the perspective of landscape sustainability, including landscape aesthetics planning, ecological protection planning and resource recycling planning, and so on. The construction of the circulatory system includes the circulation of farmland system, the circulation of agricultural and pastoral system and the classification of garbage. The ecological agriculture supported by these three measures can inherit the essence of traditional Chinese agriculture while promoting modern information technology, biotechnology and other modern science and technology. In the application of agriculture, they are also conducive to promoting the construction and development of agriculture and related laws and regulations. The explicit proposal of these measures is to provide a theoretical basis for the construction of ecological agriculture.

\section{STRATEGIES FOR CONDUCTING AND EXPORTING RURAL ECOLOGICAL CONSTRUCTION}

Ecological construction not only needs to shape the spiritual and cultural connotation, but also should expand the influence of construction through various communication strategies based on the construction of industrial operation carriers and ecological civilized behaviors. In addition to production efficiency, modern ecological agriculture also attaches great importance to its ecological benefits and aesthetic functions [4]. It is needed to implement the ecological construction development strategy and create a rural specialty industry. In order to achieve this goal, it is necessary to implement follow some principles, such as the basic principle of "one village one theme and one village one special feature", the sustainable development principle of respecting nature and ecological priorities, the principle of adjusting measures to local conditions, principle of locating accurately, highlighting features, building brands and developing differentially. The specific strategies are as follows:

\section{A. Economic strategy}

A reasonable industrial structure is a prerequisite for the realization of beautiful countryside and the economic strategy in design is partly a prediction of the development after the adjustment of the existing industry mode. Based on the integration and reorganization of functions, it is feasible to introduce "sharing economy mode" as the basic concept of industrial adjustment, take the linking cycle system of agricultural breeding as the core of the existing mode, vigorously develop the industry mode that pays equal attention to the tertiary industry and focus on creating culture industry.

The second part of the economic strategy is to link the agriculture-centric industry chain to the tertiary industry, including production, trading, experience, service, display, 
scientific research, business, leisure, etc. This includes various projects, such as industrial farmland, agricultural trade market, ecological picking and experiential farmland, catering and entertainment, cultural exhibition center, ecological water purification system and wind-solar hybrid power generation, commercial entertainment along the street, agritainment and riverside water trails, with the purpose to form a cultural industry chain with agriculture as the core covering the whole industry.

\section{B. Ecological strategy}

The ecological strategy includes four parts: agricultural circulation and sewage treatment, soil restoration of farmland, construction of ecological greenhouses and construction of digital pig houses.

The agricultural circulatory system is to establish a circulation system for agriculture and local aquaculture, so that the agricultural waste and excreta from farms can make use of each other to achieve transformation to produce organic fertilizers and solid fuels, forming a virtuous circle. The treatment of sewage is actually a supplement to the entire agricultural circulatory system and it is also the key part of the treatment and discharge of water in production and living. For one thing, domestic sewage can be collected by the disposal system arranged in the building agglomeration area and then degrade organic substances and ammonia, nitrogen, phosphorus and other components with sedimentation fermentation process in the treatment line. Besides, the agricultural wastewater can be uniformly collected and treated through the channels arranged in the farmland. It is also feasible to set infiltration trenches and directly implement the soil infiltration treatment in the low-pollution roads to fully utilize the water and fertilizer resources.

Soil pollution in farmland is a problem that cannot be ignored in rural reconstruction. Unreasonable cultivation of farmland and pollution from water sources often cause pollution to farmland. Remediation of soil is often carried out in high-intensively planted areas, with bioremediation. Adding biochar in the soil and planting hyper accumulator in the farmland can reduce the content of pollutants such as chromium and cadmium in the soil, updating the original soil in the village and improving crop quality.

The construction of ecological greenhouses is a resourcesaving and efficient agricultural technology system that gradually develops in recent years. The principle is to form an eco-agriculture circulatory system through the treatment and reuse of straw, manure and aquaculture generated in breeding process and organic fertilizer. This new type of greenhouse design and planting-and-breeding mode fully promote the true integration of social benefits, ecological benefits and economic benefits.

The new pigsty adopts the digital breeding system. It can be seen from the selection of pig houses, the technology of negative-pressure water curtain cooling and the setting of underground fermentation mattress materials that, the pig breeding site is truly realize a ideal clean status, with no pollution, no malodour and no bacteria. The digital breeding system in the pigsty automatically and accurately feeds the individual sows through wireless identification. In addition, the automatic temperature control system and pig farm data management and analysis library are also provided in the pigsty.

\section{Space strategy}

Proceeding from the perspectives of space, culture and ecology, it is needed to analyze the existing problems in the village and propose new visions on this basis. The first vision is to integrate existing chaotic spatial conditions and create a well-planned village environment, so as to provide a balanced lifestyle. The second vision is to integrate the cultural life of the Han nationality and She Nationality into a development state in which they are dependent on and coordinated with each other. The third vision is to strengthen the links between agriculture and breeding industry to make full use of resources and establish a circular ecosystem of agriculture - breeding agriculture.

It is necessary to reward the locals in line with local conditions, encourage the inheritance and return of traditional beliefs, apply ecological planning in villages to achieve the agriculture regeneration in villages and establish a business model for sustainable development. In terms of the design and implementation of space strategy, the construction of beautiful countryside can be promoted through the design and implementation of point-to-point details.

The first point: the restoration of villages' overall vitality includes the increase of public green space, places for cultural reading and sports facilities.

The second point: the improvement of villagers' living standards includes improving the sanitation of the villages, rebuilding and renewing of buildings in the villages and increasing the accessibility of infrastructure.

The third point: linking village cultural exchanges includes creating space for neighborhood communication, creating a national culture atmosphere and reusing the old facilities in the villages.

The fourth point: the further improvement of villages' infrastructure construction includes the new construction of health clinics, the protection and inheritance of historic structures and the renovation of the site lighting system.

\section{Design strategy}

The design strategy includes four parts: reconstruction of wetland and embankment, rainwater collection and management system, wind-solar hybrid power generation and classified processing of waste.

The riverbank has been reconstructed for the consideration of landscape factors and village ecology. The aquatic plants like the hydrilla, tape grass, reed and calamus can be selected to decontaminate the riverbed and embankment through the layered and fixed plants as well as the gentle slope-covered soil. In addition, constructed wetlands should be set up in the villages. On the one hand, they can process the tail water of the rainwater collection system and the initial filtrated water of the sewage treatment route. On the other hand, they can be used as 
the sightseeing and wetland landscape. Rainwater, as the resource most easily overlooked, is often treated together with other resources, resulting in waste of a large amount of water. The strategy is to establish a system to divide rain and sewage on the site. A rainwater collection system can be set up to collect and pre-treat the rainwater from buildings and roads. After the treated water reaches the standard of reclaimed water, it can satisfy the need for agricultural irrigation and nonpotable water. Rainwater from constructed wetlands can be guided to flow into the river through artificial waterways, which greatly can improve the ecological benefits of the site.

Building energy efficiency is an inevitable requirement for the sustainable development of beautiful countryside and also an optimal use of resources. The historic buildings on the site mainly use light energy in the form of BIPV, and these new buildings are mainly photovoltaic ones. The energy-saving efficiency is optimized through wind-solar complementation and other forms.

In terms of the disposal of garbage, the garbage generated by residents is divided into two categories, kitchen waste and household garbage. Through sieving, fermentation, belt filter presses, pyrolysis furnaces and other technologies, the waste is converted into electrical energy and organic fertilizers, facilitating buildings and farmland.

\section{CONCLUSION}

It is needed to resolve problems in the village development one by one and defuse the contradictions in rural development through the planning and governance of the current environmental issues in rural areas, so as to create a good environment for the locals based on the rural ecological environment and ecological agriculture. The practical measures include solving the problem of environmental pollution of villages from the source, forming the cyclic industry chain of agriculture-breeding-agriculture, innovating in the rural economic business mode, inheriting and promoting traditional culture and activating the village's overall vitality. The aim is to create a well-planned village space, focus on building an ecological, harmonious and beautiful countryside, pay back in line with local conditions to provide a coordinated and balanced production lifestyle for the villagers, creating a green and sustainable overall regional ecosystem and building beautiful countryside with good ecological cycle.

\section{REFERENCES}

[1] Yu Kongjian, Li Dihua. The Landscape Ecological Model of Urban and Rural Areas and Regional Planning [J]. Foreign Urban Planning Forum, 1997 (3): 27-31.

[2] Wang Yanglin. The Sustainability of Agriculture and the Landscape Approach to Its Realization [J]. Territorial Development and Remediation, 1995(4): 1-4

[3] Li Xintong. The Landscape Ecological Planning and Design for Sustainable Agriculture [J]. Areal Research and Development, 2000(03).

[4] He Junbin. Study on the Constitution of Ecological Agriculture Landscape [N]. Journal of Hunan University of Humanities Science and Technology. 2008(06). 